\title{
Sonority and syllable structure: The case of Burmese tone
}

\author{
Kate Mooney \& Chiara Repetti-Ludlow*
}

\begin{abstract}
The relationship between tone and sonority has been a recurrent theme in the literature over recent years, raising questions of how suprasegmental features like tone interact with segmental or prosodic qualities, such as vowel quality, sonority, and duration (de Lacy 2006; Gordon 2001). In this paper, we present an original phonetic study that investigates the relationship between tone, vowel quality, and sonority in Burmese. These are not simple to disentangle in Burmese, since the language has a unique vowel alternation system where certain vowels can only combine with certain tones or codas. While some researchers have analyzed these alternations as directly stemming from tone itself (Kelly 2012), we argue that the vowel alternations are toneindependent. We propose that the Burmese vowel alternations follow from general preferences on sonority sequencing (cf. Clements 1990), and so there is no need for tone and segmental quality to interact directly. Not only does this explain the complex vowel system of Burmese, but this proposal casts a new view on recurrent issues in Burmese phonology, such as the representation of underlying tonal contrasts and minor syllables.
\end{abstract}

Keywords. tone; sonority; Burmese; centralization; diphthongization; minor syllables

1. Introduction. Burmese is a Sino-Tibetan language spoken throughout Burma/Myanmar by approximately 30 million people as a first language and another 10 million people as a second language (Watkins 2001). Although the phonetics and phonology of the language are relatively well-studied, the question of classifying Burmese tone has posed a problem for researchers for over a century (cf. Stewart 1936; Sprigg 1964; Richter 1967; Bradley 1982; Tun 1982). This is due, in large part, to the fact that Burmese tone is not classifiable exclusively by pitch contour. Rather, researchers like Bradley (1982) and Watkins (2001) have claimed that the main correlates of tone are phonation type, duration, and pitch, while others, like Kelly (2012), have posited that vowel quality is also a main correlate of Burmese of tone, suggesting that tone interacts with the realization of individual segmental phonemes. Furthermore, researchers have noted that part of the challenge of studying Burmese tone lies in the fact that there are likely effects of tonal sandhi that further alter the pronunciation of both the tone and neighboring segments (Watkins 2000), although no systematic studies of tonal interactions in Burmese have been done to the best of our knowledge.

Despite the controversy over the main correlates of tone, researchers largely agree that tone falls into four major categories, which Watkins (2000) calls "low", "high", "creaky", and "killed". Several other researchers including Richter (1967) and Bradley (1982) also make the case for a 4-tone system, despite describing the tonal cues differently. Ultimately, researchers agree that the low tone generally starts with a low pitch, the high tone starts

\footnotetext{
${ }^{*}$ Special thanks to Gillian Gallagher, Maria Gouskova, and audiences at NYU PEP Lab and LSA 2021 for comments. Authors: Kate Mooney, New York University (mooney@nyu.edu) \& Chiara Repetti-Ludlow, New York University (chiararepettiludlow@nyu.edu).
} 
with a high pitch, the creaky tone has a weak glottal stop or creak, and the killed tone has a high onset pitch but is very short due to the presence of a full glottal stop coda.

Watkins (2000) also argues that there is a distributional constraint on what vowels can appear with what tones; Set A: [a, e, $\varepsilon, \mathrm{i}, \mathrm{o}, \mathrm{\rho}, \mathrm{u}]$ (in open syllables), and Set B: [e, eI, aI, I,

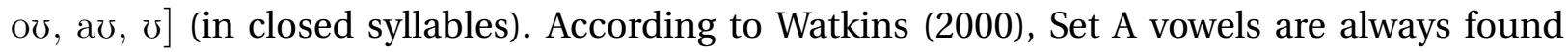
in open syllables, while Set B vowels are found in syllables closed by nasalization or the killed tone. Thus, modal low, high, and creaky tones can appear with only the first set of vowels, while the killed tone and nasal low, high, and creaky tones can only appear on the second set of vowels. The Burmese vowel inventory is summarized in (1) and the consonant inventory is ssummarized in (2).

(1) Burmese vowel inventory as described in Watkins (2000)

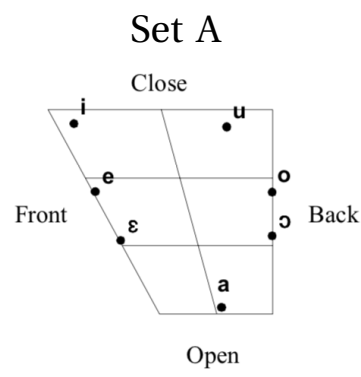

Set B

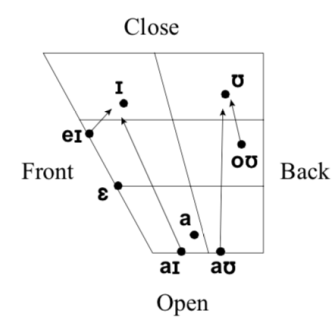

(2) Burmese consonant inventory as described in Watkins (2001)

\begin{tabular}{|c|c|c|c|c|c|c|c|}
\hline & Labial & Dental & Alveolar & Postalveolar & Palatal & Velar & Glottal \\
\hline Plosive/Affricate & b p ph & & $\mathrm{d} \mathrm{t} \mathrm{t}^{\mathrm{h}}$ & $\mathrm{d}_{3} \mathrm{t} \int \mathrm{t} \mathrm{h}^{\mathrm{h}}$ & & (9 k k kh & $?$ \\
\hline Nasal & $\mathrm{m} \mathrm{m}$ & & $\mathrm{n} \mathrm{n}$ & & $\mathrm{n} \stackrel{\circ}{n}$ & y & \\
\hline Fricative & & ð $\theta$ & $\mathrm{ZS} \mathrm{S}^{\mathrm{h}}$ & $\int$ & & & $\mathrm{h}$ \\
\hline Approximant & $\mathrm{W} M$ & & & & $\mathrm{j}$ & & \\
\hline Lateral & & & 11 & & & & \\
\hline
\end{tabular}

1.1. Proposal. Building on previous work on vowel quality, tone, and syllable structure, we argue that the vowels in Set B are derived from the vowels in Set A in closed syllables (Figure 1). These changes are predictable from syllable structure, with high and low vowels centralizing in closed syllables, and mid-vowels diphthongizing in closed syllables. While previous researchers have argued that these alternations are not easily unifiable (Gruber 2011), we argue that there is a common core; sonority. Closed syllable nuclei either lax or diphthongize in order to minimize their sonority adjacent to a coda. We propose that this alternation stems from a cross-linguistic preference for there to be minimal sonority differences between the nucleus and coda (cf. Sonority Sequencing Principle, Clements 1990).

One implication of this proposal is that Burmese may only have three tones: high, low, and creaky (CV). The three underlying tones are found in both open and closed syllables, but the syllable nucleus centralizes or diphthongizes when there is a nasal or glottal stop coda. It is possible that the killed tones are underlyingly a high tone with a glottal stop coda, and undergo tonal contour alternations that minimize sonority adjacent to the glottal coda in isolation. In earlier work, creaky and killed tones were found to have nearidentical tonal contours - in the following sections, we will see that this is not always the 
case, which forms the phonetic basis for giving creaky and killed tones different underlying tonal specifications. In turn, this provides the basis for our argument that two vowel systems are not necessary to account for tonal data.

The remainder of the paper is organized as follows: Section 2 presents two acoustic studies, which provide the phonetic evidence in favor of tone disambiguation that does not rely on vowel quality. Section 3 provides a sonority-based analysis for the Burmese vowel alternations, and shows how this enriches our understanding of minor syllables (Section 3.3) and underlying tones (Section 3.4). Section 4 concludes and discusses future directions for research.

2. Acoustic Study. In this section, we present two experiments on tonal realization in Burmese. The first experiment elicits tone in isolation, and is aimed at replicating results from previous studies with a wider variety of syllable onsets and rimes. Previous studies limited their analysis to only /a/ (e.g. Watkins 2000; Gruber 2011) or only /i/ and /a/ (Kelly 2012), and this study aimed to confirm the gen-

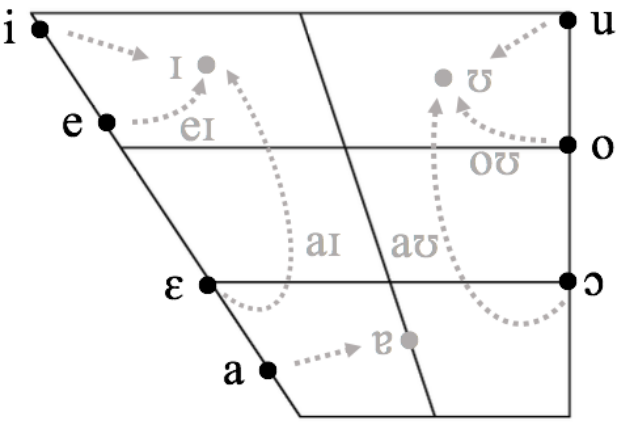
eralizations for a wider set of vowels and consonant onsets. The second experiment elicits tones in sentential frames, with the goal of explaining some of the contradic-

Figure 1. Proposed set of open syllable vowels (black) and closed syllable vowels (gray). tory F0 variation reported in previous work

(e.g. Bradley 1982; Watkins 2000; Kelly 2012). We hypothesize that some of the variability reported in tonal contours comes from sentence-level prosody, and that previous studies may have unintentionally included tokens with contrastive focus intonation. We also hypothesize that if Burmese is a language similar to Cantonese (cf. Peng et al. 2005), then sentential prosody may create sandhi-like alternations that are only predictable from underlying tonal specifications. The number of surface patterns across different prosodic contexts would thus give us a rough estimate of the number of underlying tonal distinctions needed in the language.

To sum up, the experiments in this section have two purposes: (i) to confirm findings from previous literature and extend these findings to tone in different segmental contexts (varying onset, coda, and nucleus), and (ii) to expand our understanding of how tonal contours vary under different sentential prosody. Together, these studies will allow us to assess which correlates of tone are important in creating Burmese tonal representations and whether two sets of vowels are necessary to account for the tonal variation we see.

2.1. EXPERIMENT 1: TONE in isolation. Our consultant for this project was a female native speaker of Burmese from the city of Yangon (also known as Rangoon). She is in her late 20s and has been living in the United States for approximately 10 years. In this experiment we provided our consultant with English translations of target words and asked her to repeat the Burmese translations out loud in isolation. For open syllables, target words 
consisted of the consonants $/ \mathrm{p}, \mathrm{p}^{\mathrm{h}}, \mathrm{m}, \mathrm{m}, \mathrm{t} \int /$ followed by each vowel (/a, e, i, o, u, o/). ${ }^{1}$ Wherever possible, we identified 3 minimal pairs with our informant, such as [ka] (low tone) 'protect', [ka] (high tone) 'car', and [ka] (creaky tone) 'dance'. The killed tone is only found with the closed-syllable vowels, and was left for the closed syllable analysis. We also noted that $/ \partial /$ is a vowel in the language, but only occurs in minor syllables that do not seem to carry tone (see Section 3.3). For closed syllables, target words consisted of consonants $/ \mathrm{p}, \mathrm{p}^{\mathrm{h}}, \mathrm{k}, \mathrm{k}^{\mathrm{h}}, \mathrm{m}, \mathrm{m}, \mathrm{t} \int, \mathrm{t} \mathrm{h}^{\mathrm{h}}, \mathrm{d}_{3} /$ followed by each closed-syllable vowel / $\mathrm{e}$, eI, aI,

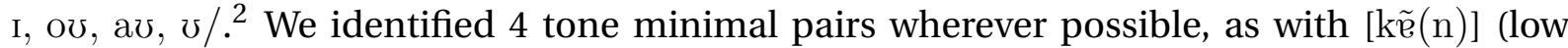

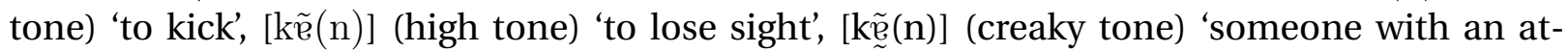
titude', and [ke?] (killed tone) 'adhesive'. The high, low, and creaky tones were all nasalized in the closed syllables, whereas the killed tones were all oral.

After gathering the recordings, each token was annotated in Praat (Boersma \& Weenink 2018) and files were run through VoiceSauce (Shue et al. 2009) in order to get measurements of duration, F0, CPP, $\mathrm{H}^{*}-\mathrm{H} 2 *$, and $\mathrm{H}^{*}-\mathrm{A} 1 *$. Measurements were taken at every millisecond of the token. Once this data was compiled, a linear mixed effects regression was conducted using the lme4 package (Bates et al. 2014) of RStudio (RStudio 2015).

2.1.1. Results: TONE in isolation. The results from the linear mixed effects regression analysis show that duration, $\mathrm{CPP}, \mathrm{H} 1{ }^{*}-\mathrm{H} 2 *$, and $\mathrm{H} 1{ }^{*}-\mathrm{A} 1 *$ were all significant predictors in distinguishing the four tones for both open and closed syllables. Only pitch was not significant in differentiating all four tones. For the purposes of this project, we will focus on F0 and duration, and leave discusssion of $\mathrm{CPP}, \mathrm{H}^{*}-\mathrm{H} 2^{*}$, and $\mathrm{H}^{*}-\mathrm{A} 1^{*}$ to future work. Figure 2 shows a comparison in F0 and duration between low, high and creaky tones over normalized time.

As Figure 2 shows, high and low tones have much longer durations than creaky and killed tones. Furthermore, nasal syllables tended to be a bit shorter than their oral counterparts. F0, although not significant in distinguishing all four tones, demonstrates consistent patterns with the creaky, killed, and high tones; rising and then falling, while the low tone falls and then rises. This led us to the question of whether F0 would be significant in comparing only two tones at a time. In order to test this, we first directly compared high and low tones, finding that F0 emerges as a significant variable. We then compared creaky and killed tones, again finding that F0 is a significant cue in distinguishing these tones. This suggests that both F0 and duration are important cues for distinguishing the tones of Burmese, and that vowel quality might not be necessary to distinguish creaky and killed tones.

After comparing the tones to each other, we compared the pitch contour of tones in (open) oral and (closed) nasalized syllables. When comparing only among nasal syllables, the linear mixed effects regression analysis showed that all cues were significant, including both duration and F0. This suggests that F0 might be more salient in nasal than oral

\footnotetext{
${ }^{1}$ We found no evidence of surface $/ \varepsilon /$, contra Watkins (2000). We analyze this as a surface merger between /e/ and $/ \varepsilon /$ in open syllables, but this certainly deserves more attention moving forward.

${ }^{2}$ Note that the closed vowel counterpart of $/ \varepsilon /$ is $/$ aI/. Unlike $/ \varepsilon /$, this occurs on the surface, and does not neutralize to /e/ or /er/ in closed syllables. One potential description of the realization of /ai/ but not $/ \varepsilon /$ is that there is a high-ranked ${ }^{*} \varepsilon$ constraint, and so the underlying contrast is neutralized in open syllables by violating IDENT (ATR). Another possibility is diachronic - perhaps /e/ and $/ \varepsilon /$ merged, but /eI/ and /aI/ remained fossilized in closed-syllable lexical items.
} 
syllables. Although the tonal contours are relatively similar in nasal and oral counterparts, there are some differences, as can be seen in Figure 2. For example, nasalized syllables with the high tone showed a sharp fall that differed from its fall to mid-rise contour in oral syllables. Meanwhile, although low tones retained the same contour when nasalized, the timing of the peaks and troughs shifted leftwards. Creaky tones, like high tones, also had a different pitch contour when nasalized. Thus, we find that different acoustic cues may be weighted differently depending on the syllable type.

To summarize, we found that when all four tones are grouped together, duration, $\mathrm{CPP}, \mathrm{H}^{*}-\mathrm{H} 2^{*}$, and $\mathrm{H}^{*}{ }^{*} \mathrm{Al}^{*}$ are significant predictors. However, upon subdividing the tonal categories further, F0 emerged as a significant variable. These findings are largely in line with previous research on Burmese tone, especially from Kelly (2012). We also directly compared open and closed syllables in Burmese, finding that closed syllables were generally shorter than oral ones and have slightly different tonal contours such that F0 becomes a significant predictor for tone on nasal syllables. Finally, and perhaps most significantly for the question at hand, we found that F0, $\mathrm{CPP}$, and $\mathrm{H}^{*}$ - $\mathrm{H} 2 *$ significantly differentiate creaky and killed tones, which suggests that we do not need to rely on two sets of vowels to disambiguate the tones.

\subsection{EXPERIMENT 2: TONE In SENTENTIAL} CONTEXTs. Eliciting tone in isolation is

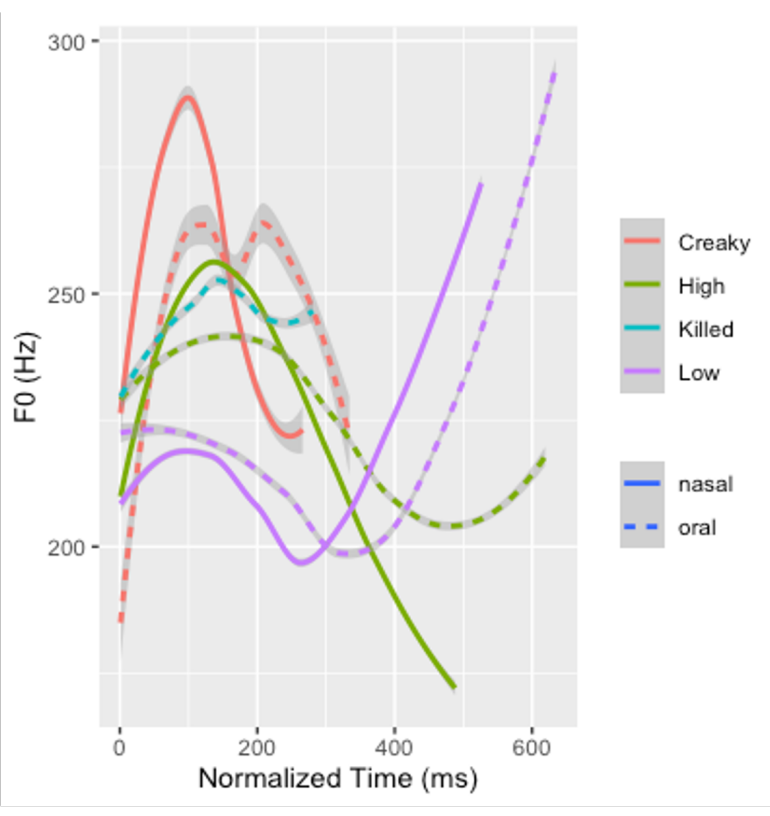

Figure 2. Average F0 and duration for tones in nasal and oral syllables. known to be problematic in many languages, since tokens in these contexts are often (a) contrastively focused and (b) phrasefinal (cf. Peng et al. 2005; Coupe 2014; a.o.). To account for this, we also elicited the four tones in sentential contexts under varying prosodic conditions. We created six sets of sentential frames, three with verbs and three with nouns, where the target word was always phrase-medial. We tested four prosodic conditions: (1) the lexical item in isolation (as a control), (2) in a declarative sentence, (3) in a sentence with contrastive focus on the target item, and (4) in a polar question, each of which might be expected to have different tonal contours. We then took the same measures as in the tone in isolation analysis.

2.2.1. RESULTS: TONE IN SENTENTIAL CONTEXTS. Ultimately our findings showed that syllables in isolation were much longer than syllables in a sentential context. In sentential contexts, durational distinctions are largely neutralized. In fact, in contrastive sentences, duration does not even reach significance in distinguishing between tones. However, pitch is a significant cue in all three sentential contexts, suggesting this this cue is the most robust. The average pitch contours and durations can be seen in Figure 3. 
While some of the pitch distinctions in isolated tones may seem hard to distinguish with a shorter duration, in many cases the pitch contour actually changes, creating greater contrast. For example, while creaky and killed tones largely follow the same pitch contour in isolation, in sentential contexts they have different contours, with killed tones starting around $250 \mathrm{~Hz}$ and rising and creaky tones starting at about $275 \mathrm{~Hz}$ and falling. Unlike tone in isolation where the low tone falls and then rises and the high tone rises and then falls, in sentential contexts the low tone only falls and the high tone only rises. Although the creaky and low tones both fall in pitch, they are easily distinguishable by their ranges, with the low tone having a much lower start and end pitch than the creaky tone and generally a longer duration. Meanwhile, the killed and high tones both rise throughout the vowel, but once again general pitch range is a helpful distinguishing factor, as the killed tone starts at a higher pitch and rises more than the high tone. The high tone is also generally a bit longer than the killed tone.

Thus, we have expanded our understanding of how tone behaves in different sentential contexts and also provided some evidence that the killed tone patterns closely with the high tone in sentential contexts. Furthermore, we have shown that vowel quality is not necessary to distinguish creaky and killed tones, especially in sentential contexts where they have markedly different pitch contours. This opens up the possibility that vowel quality need not be a part of the tonal system, but rather, it can be derivable from the segmental string and syllable structure.

\section{Analysis: Vowel alternations and sonor-} ity. In this section, we present a unified analysis of Burmese vowel alternations shown in (3). In previous work (e.g. Kelly 2012), some of these alternations had been argued to be crucial parts of the underlying tonal specification. In Section 2.2, we showed that creaky and killed tones differ in pitch contour as well as vowel quality, and so there is no need for these vowel alternations to be underlyingly specified. Instead, we argue that the Burmese vowel alternations in (3) are predictable and phonologically generated (contra Gru-

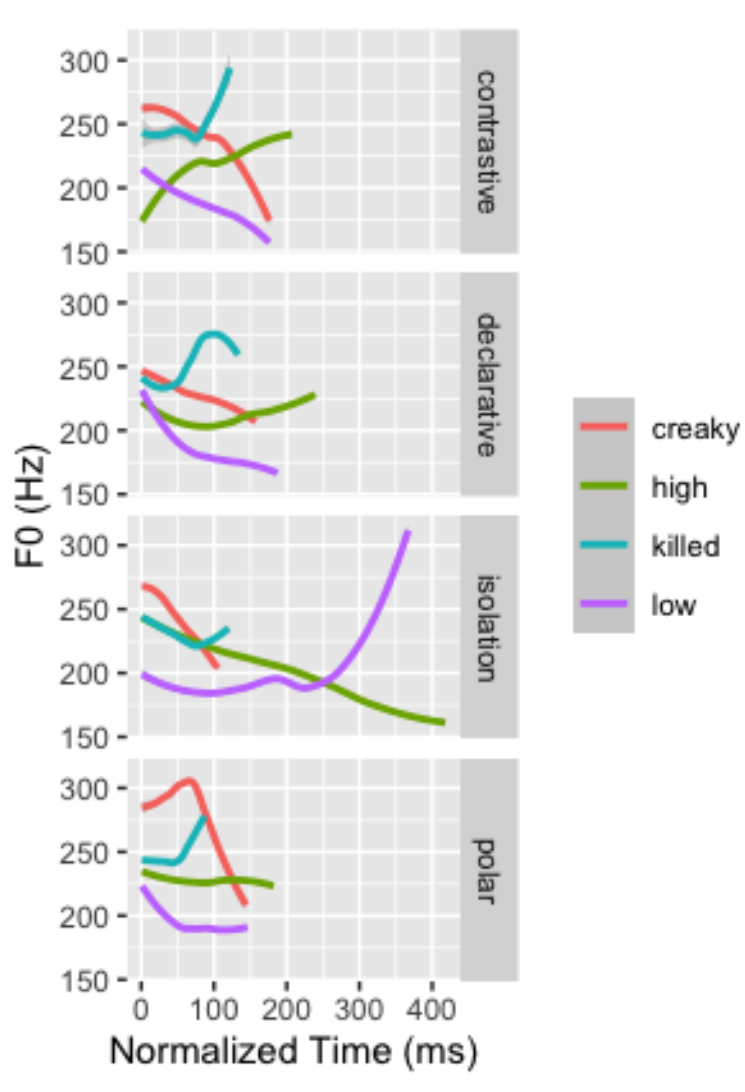

Figure 3. Effect of prosodic context on F0 contour and duration for tones elicited in sentential frames or isolation. ber 2011) and follow from universal preferences on sonority. This has two major consequences: (i) Burmese has vowel alternations based on syllable type, and (ii) Burmese is no longer a language with tone-vowel quality 
interactions, and so is not a counterexample for the universal that segment-tone interactions must go through a prosodic intermediary (cf. de Lacy 2006).

\begin{tabular}{|c|c|c|c|c|}
\hline \multirow{2}{*}{$\begin{array}{c}\text { Open syllables } \\
\text { High open }(\mathrm{CV})\end{array}$} & \multicolumn{4}{|c|}{ Closed syllables } \\
\hline & High na & $\mathrm{l}(\mathrm{CVN})$ & Killed & CV?) \\
\hline $\mathrm{p}^{\mathrm{h}} \mathrm{i} \quad$ 'to comb' & $\mathrm{p}^{\mathrm{h}} \widetilde{\mathrm{I}}(\mathrm{n})$ & 'to roll out' & $\mathrm{k}^{\mathrm{h}} \mathrm{I} ?$ & 'decade' \\
\hline 'to separate' & $\mathrm{p}^{\mathrm{h}} \tilde{\mathrm{eI}}(\mathrm{n})$ & ‘drugged’ & $\mathrm{p}^{\mathrm{h}} \mathrm{eI} ?$ & 'to break' \\
\hline $\mathrm{k}^{\mathrm{h}} \varepsilon$ & $\mathrm{k}^{\mathrm{h}} \tilde{\mathrm{a}} \tilde{\mathrm{I}}(\mathrm{n})$ & 'give order' & $\mathrm{k}^{\mathrm{h}}$ aI? & 'knock into s.t.' \\
\hline 'frog' & $\mathrm{p}^{\mathrm{h}} \tilde{\mathrm{e}}(\mathrm{n})$ & ‘catch’ & $\mathrm{p}^{\mathrm{h}} \mathrm{p} ?$ & ‘hug’ \\
\hline 'grandpa' & $\mathrm{p}^{\mathrm{h}} \tilde{\mathrm{O}} \tilde{\mho}(\mathrm{n})$ & 'phone' & $\mathrm{p}^{\mathrm{h}} \mathrm{Ov?}$ & 'grill fruit' \\
\hline 'abundant' & $\mathrm{p}^{\mathrm{h}} \mathrm{a} \tilde{\mho}(\mathrm{n})$ & ‘airy’ & $\mathrm{p}^{\mathrm{h}} \mathrm{av} ?$ & 'poke/open' \\
\hline $\mathrm{p}^{\mathrm{h}} \mathrm{u} \quad$ 'little buds' & $\mathrm{p}^{\mathrm{h}} \tilde{\mho}(\mathrm{n})$ & 'cover up’ & $\mathrm{p}^{\mathrm{h}} \mathrm{s}$ & 'type of lizard' \\
\hline
\end{tabular}

We propose that while Burmese generally prefers the less-marked vowels [i, e, $\varepsilon$, a, $\mathrm{o}, \mathrm{\rho}, \mathrm{u}]$, closed syllables create a context where sonority preferences shift, allowing diphthongs [eI, aI, ov, av] and low-sonority vowels [I, e, $\mho]$ to surface. This pattern directly follows from Clements (1990)'s Sonority Sequencing Principle (SSP), where codas prefer to minimize their sonority difference with the syllable nucleus. In most languages, the Sonority Sequencing Principle is realized by making codas more sonorous (Parker 2002), but in Burmese, this pattern is reversed: nuclei will lower their sonority to minimize the sonority differences between nucleus and coda. Burmese is not alone in this pattern - Javanese (Adisasmito-Smith 1999) and Slovak (Rubach 1993) show similar vowel alternations based on whether a syllable is open or closed.

Following de Lacy (2006), we assume the sonority hierarchy in (4): codas are only permitted following segments with sonority $\leq 1$.

(4) Sonority Hierarchy - Vowels

(following de Lacy, 2006: 286)

$$
\begin{aligned}
& \begin{array}{llllllll}
\text { More sonorous } & 5 & 4 & 3 & 2 & 1 & 0 & \text { Less sonorous }
\end{array} \\
& \text { a } \varepsilon, \supset \text { e, o i, u } \frac{\mathrm{I}, \mho, \mathrm{e} \quad \text { ə }}{\text { codas }} \\
& \text { permitted }
\end{aligned}
$$

In schematic form, this means that Burmese high and low vowels centralize (black lines), but mid vowels diphthongize (dotted lines) in order to reach sonority targets I, $v, \gtrless$ (shaded cells). Schwa, while present in the language, cannot be tone-bearing (see Section 3.3).

(5)

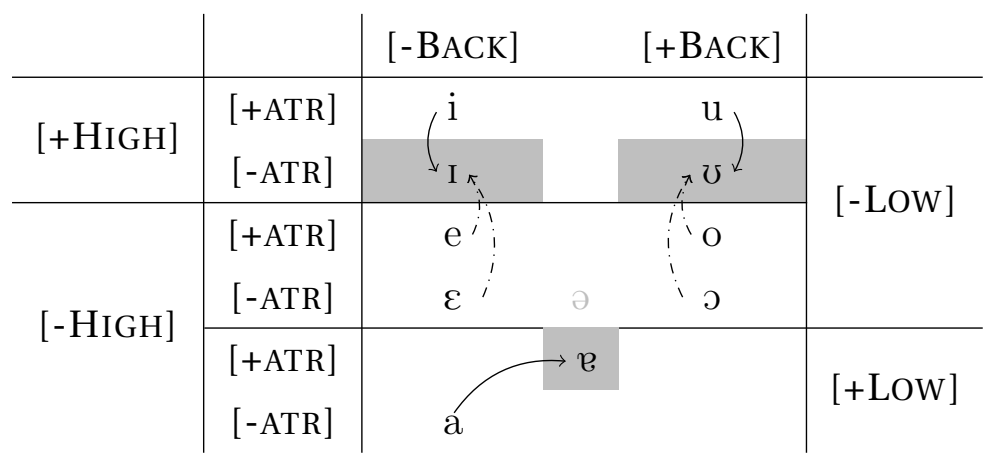


To sum up, we propose that Burmese has a single vowel system, and that the alternations are independent of tone. Instead, vowel alternations are driven by a pressure to create a sonority plateau between nucleus and coda, which results in nucleus centralization or diphthongization. We cast our analysis in Parallel Optimality Theory (Prince \& Smolensky 1993, 2004).

The section is structured as follows: Section 3.1 presents the analysis of vowel centralization and diphthongization, Section 3.2 discusses opacity with nasal coda deletion. We then discuss implications this has for our understanding of minor syllables (Section 3.3) and the tonal system of Burmese (Section 3.4).

3.1. ANALYSIS: VOWEL CENTRALIZATION AND DIPHTHONGIZATION. Burmese prefers for there to be a sonority plateau between nucleus and coda. In closed syllables, this creates a pressure for nuclei to lower their sonority, which allows low-sonority vowels (I, $v$, e) to surface. However, vowel height cannot change in Burmese, and so while high and low vowels can centralize to reach these low-sonority targets, mid vowels must diphthongize through breaking (cf. Rubach 1993; a.o.).

To represent the preference for a sonority plateau between nucleus and coda, we propose the constraint CODA-SON:

(6) CODA-SON: 'The sonority of a [-CONSONANTAL] nucleus adjacent to a [+CONSONANTAL] coda must be 1 or less.' see sonority hierarchy in (4)

We also propose $* \mathrm{~V}_{\mathrm{I}, v, \mathrm{e}}$, a sonority-based markedness constraint on tone-bearing vowels. Intuitively, tones prefer to dock on vowels with greater sonority. In Burmese, docking on vowels with sonority of 1 is dispreferred $\left({ }^{*} \mathrm{~V}_{\mathrm{I}, v, q}\right)$. (Tones cannot dock at all on schwa, sonority $=0$, see Section 3.3.) Parallels to this exist in stress languages as well, where stress prefers to dock on higher-sonority vowels (e.g. Takia, de Lacy 2006).

(7) ${ }^{*} \hat{V}_{\mathrm{I}, \mho, \mathrm{Q}}:$ (dominated) Assign a violation for a tone-bearing vowel with a sonority of 1 .

We first account for the vowel centralization cases. In high and low vowels, no change in height is needed to reach the low-sonority targets [I, $v, \gtrless]$, only a change in [ATR]. We introduce the constraint IDENT(ATR), which is dominated in the language:

(8) IDENT(ATR): Assign a violation for a $[ \pm$ ATR] specification in the input that does not have a matching correspondent in the output.

In a simplified derivation (9), we derive $/ \mathrm{k}^{\mathrm{h}} \mathrm{i} \mathrm{P} / \rightarrow\left[\mathrm{k}^{\mathrm{h}} \mathrm{I}\right.$ ] 'decade' from (3). We table the question of underlying tone for the time being (see Section 3.4). CODA-Son outranks IDENT(ATR), and so a high vowel will centralize in a closed syllable.

(9)

\begin{tabular}{|r|c|c|c|}
\hline$/ \mathrm{k}^{\mathrm{h}} \mathrm{i} /$ & CODA-SON & ${ }^{*} \hat{\mathrm{V}}_{\mathrm{I}, \mho, \mathrm{e}}$ & IDENT(ATR) \\
\hline \hline $\mathrm{a} . \mathrm{k}^{\mathrm{h}} \mathrm{i} i$ & $* !$ & & \\
\hline b. & & $* !$ & $*$ \\
\hline
\end{tabular}

In open syllables, CODA-SON does not apply, and so low-sonority vowels will tense. This is shown in the derivation of [ $\left.\mathrm{p}^{\mathrm{h}} \mathrm{i}\right]$ 'to comb' in (10). 
(10)

\begin{tabular}{|c|c|c|c|}
\hline$/ \mathrm{p}^{\mathrm{h}_{\mathrm{I}} /}$ & CODA-SON & ${ }^{*} \hat{\mathrm{V}}_{\mathrm{I}, v, \mathrm{e}}$ & IDENT(ATR) \\
\hline a. $p^{h}{ }_{I}$ & & $* !$ & \\
\hline 鼍 b. $\mathrm{p}^{\mathrm{h}_{\mathrm{i}}}$ & & & $*$ \\
\hline
\end{tabular}

In low vowels, centralization coincides with vowel backing. In the derivation of $\left[\mathrm{p}^{\mathrm{h}} \mathrm{r}\right.$ ?] 'hug', the centralized candidate wins, even though it has violations of IDENT(ATR) and MAX(BACK). We assume candidates like *[phæ?] are ruled out by an undominated *æ constraint.

\begin{tabular}{|c|c|c|c|c|}
\hline$/ \mathrm{p}^{\mathrm{h}} \mathrm{a} \mathrm{P} /$ & CODA-SON & $* \hat{V}_{\mathrm{I}, \mho, \mathrm{e}}$ & IDENT(ATR) & MAX(BACK) \\
\hline a. $p^{h} a ?$ & $* !$ & & & \\
\hline 实 b. $\mathrm{p}^{\mathrm{h}} \mathrm{p}$ ? & & $* !$ & $*$ & $*$ \\
\hline
\end{tabular}

We now turn to the mid-vowels, which diphthongize in closed syllables. Only mid vowels diphthongize because in order to reach $\mathrm{I}, v, \imath$, mid vowels would need to change [HIGH] or [LOW]. Burmese does not permit changes to vowel height.

We argue that diphthongization arises from breaking, a type of vowel splitting (cf. Rubach 1993). In this case, an underlying vowel splits into two components, violating INTEGRITY (McCarthy \& Prince 1995), but crucially not violating IDENT. The first member of a diphthong must match its input vowel in [ \pm ATR] and $[ \pm \mathrm{HIGH}$, while also maximizing its own sonority. The second member of a diphthong must match the input vowel in [ \pm LOW], $[ \pm$ ROUND], and $[ \pm$ BACK], but minimize its own sonority. This is schematized in (12):

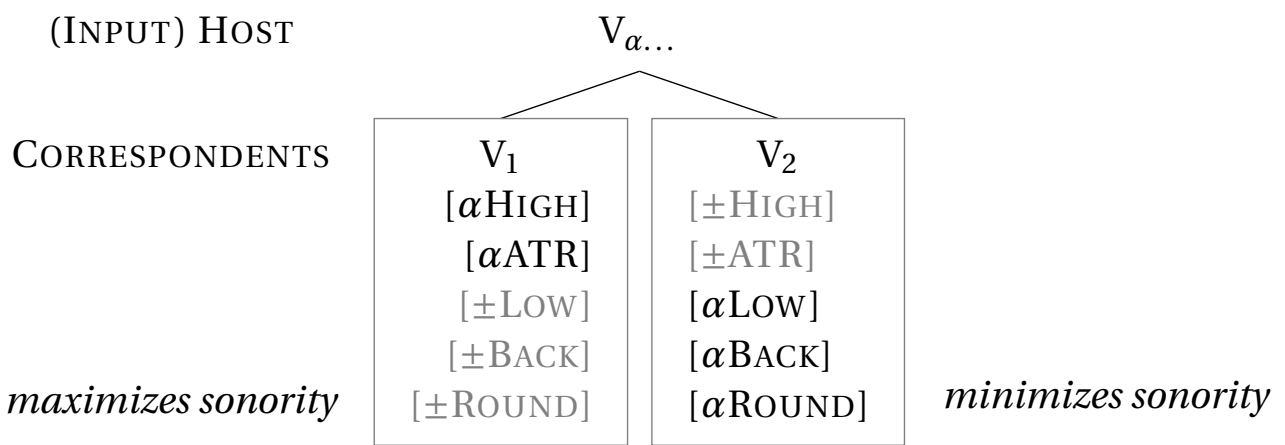

In this type of analysis, breaking must be motivated only for mid-vowels, since only mid-vowels diphthongize. This, we argue, is driven by the fact that there is no low-sonority mid vowel, and that IDENT(High, LOW) is undominated. Thus, the only way to remove a CODA-MID violation is to break, even though INTEGRITY is ranked above IDENT(ATR). We introduce the constraints INTEGRITY and IDENT(HIGH, LOW):

(13) InTEGRITY: No element in $\mathrm{S}_{1}$ has multiple correspondents in $\mathrm{S}_{2}$. (McCarthy \& Prince 1995; p. 124)

(14) IDENT(High, LOW): Assign a violation for a $[ \pm \mathrm{HIGH}]$ or $[ \pm \mathrm{LOW}]$ specification in the input that does not have a matching correspondent in the output.

In a derivation, the tense mid vowel [e] diphthongizes to [eI] in [ $\mathrm{p}^{\mathrm{h}} \mathrm{eI}$ ? $]$ 'to break'. Break-

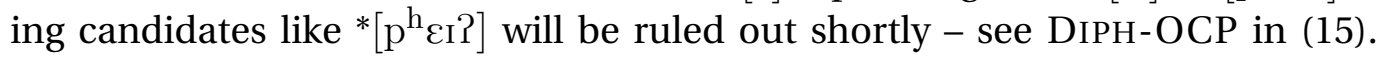




\begin{tabular}{|c|c|c|c|c|}
\hline$/ \mathrm{p}^{\mathrm{h}} \mathrm{e}_{1,2} \mathrm{l} /$ & CODA-SON & IDENT(HIGH, LOW) & INTEGRITY & IDENT(ATR) \\
\hline \hline a. $\mathrm{p}^{\mathrm{h}} \mathrm{e} ?$ & $* !$ & & & \\
\hline b. $\mathrm{p}^{\mathrm{h}} \mathrm{I}$ ? & & $* !$ & & $*$ \\
\hline 实 & & & & \\
\hline
\end{tabular}

In lax mid vowels, diphthongization still occurs, but the $\mathrm{V}_{1}$ must be realized as [a] instead of $[\varepsilon, \rho]$. We argue that this comes from a diphthong well-formedness constraint, DIPH-OCP. In order to maximize perceptibility, diphthongs are preferred when their components differ in at least two feature values out of $[ \pm \mathrm{LOW}],[ \pm \mathrm{HIGH}],[ \pm \mathrm{ATR}]$. In addition to ruling out diphthongs whose components match in height, this constraint will rule out diphthongs like $*[\varepsilon \mathrm{I}]$ and $*[\jmath \mho]$.

(15) DIPH-OCP: The $V_{1}$ and $V_{2}$ of a diphthong may only match in one feature specification out of the set $[ \pm \mathrm{LOW}],[ \pm \mathrm{HIGH}],[ \pm \mathrm{ATR}]$

In the derivation of $/ \mathrm{k}^{\mathrm{h}} \varepsilon_{1,2} \mathrm{P} / \rightarrow\left[\mathrm{k}^{\mathrm{h}} \mathrm{a}_{1} \mathrm{I}_{2} \mathrm{l}\right]$ 'knock into s.t.', DIPH-OCP rules out candidates like $*\left[\mathrm{k}^{\mathrm{h}} \varepsilon \mathrm{I}\right.$ ? $]$. In the winning candidate, no IDENT constraints are violated, because [-ATR] and [-LOW] in the input do have matching correspondents in the output - [a $]$ for $[-\mathrm{ATR}]$, and $\left[\mathrm{I}_{2}\right]$ for $[-\mathrm{LOW}]$.

\begin{tabular}{|c|c|c|c|c|c|}
\hline$/ \mathrm{k}^{\mathrm{h}} \varepsilon_{1,2} \mathrm{l} /$ & CODA-SON & IDENT(HIGH, LOW) & DIPH-OCP & INTEGRITY & IDENT(ATR) \\
\hline \hline $\mathrm{a} . \mathrm{k}^{\mathrm{h}} \varepsilon ?$ & $* !$ & & & & \\
\hline b. $\mathrm{k}^{\mathrm{h}} \mathrm{I} ?$ & & $* !$ & & & \\
\hline c. $\mathrm{k}^{\mathrm{h}} \varepsilon_{1} \mathrm{I}_{2} \mathrm{l}$ & & & $* !$ & $*$ & \\
\hline n & & & & $*$ & \\
\hline $\mathrm{d} . \mathrm{k}^{\mathrm{h}} \mathrm{a}_{1} \mathrm{I}_{2} \mathrm{l}$ & & & & $*$ & $* !$ \\
\hline
\end{tabular}

To summarize, Burmese vowel alternations are sonority-driven and predictable. Following from the Sonority Sequencing Principle, vowels reduce their sonority in closed syllables in order to create a sonority plateau between nucleus and coda. Peripheral vowels accomplish this by laxing and centralizing, but due to a restriction on vowel lowering and raising, mid-vowels must diphthongize through breaking. The final constraint ranking for this pattern is shown in (16):

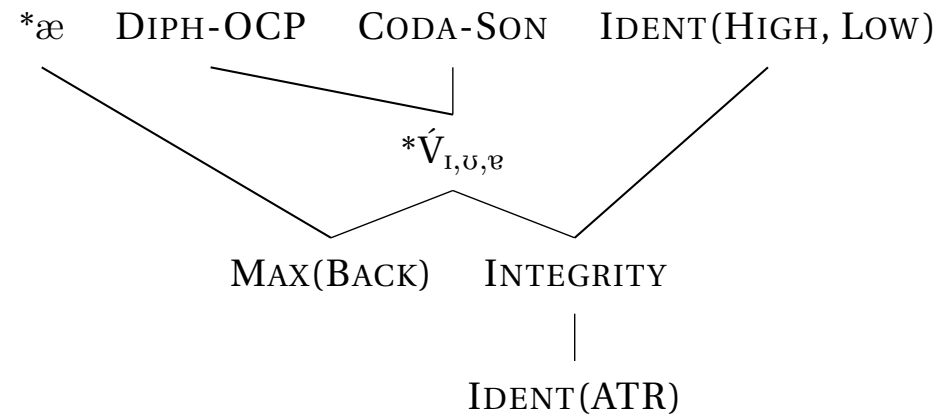

3.2. ANALYSIS: NASAL CODAS. In this section, we provide an analysis of nasal codas. Burmese nasal codas delete in phrase-final contexts, and so CVN syllables are often realized as open, nasalized syllables. Despite being phonetically open, these nasalized syllables still bear 
centralized or diphthongized vowels. This pattern is phonologically opaque: the presence of a coda conditions vowel centralization or diphthongization, but the overt coda is also removed by the phonology, thus obscuring the original conditioning environment for the vowel alternation.

In this analysis, we contend that the opacity in this pattern is due to partial deletion of a coda. We follow McCarthy (2008) in assuming that full deletion is a two-step process, (i) the deletion of a $\mathrm{C} / \mathrm{V}$ timing slot and (ii) the deletion of features. Burmese nasal coda deletion is only the deletion of a $\mathrm{C}$ timing slot - nasal features are not deleted, but instead become suprasegmental, spreading leftwards to the preceding V-slot and nasalizing it. This process doesn't affect the application of CODA-SON. The features of the nasal coda are still adjacent to underlying vowel features, and so CODA-SON will still be violated unless diphthongization or centralization occurs. This is schematized in (17):

(17) Representation of $\left[\mathrm{p}^{\mathrm{h}} \tilde{\mathrm{I}}\right]$ 'to roll out'

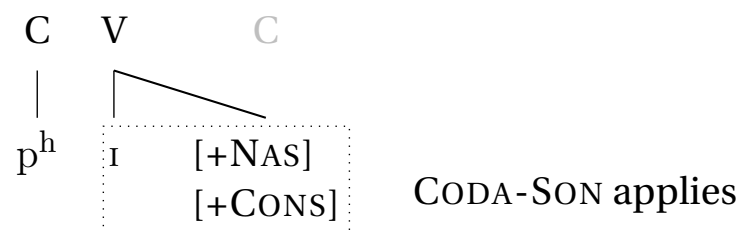

We introduce two constraints, N-CODA and MAX-CSLOT. N-CODA militates against phrase-final nasal codas and dominates MAX-CSLOT, forcing C-slot deletion in those cases. We also assume that there are undominated constraints MAX(NASAL) and *FLOAT (Zoll 1994), which prevent nasal features from deleting fully or remaining delinked.

(18) a. *N-CODA: 'Assign a violation for a C-slot associated with a [+NASAL] feature that occurs at the end of a phonological phrase $\left({ }^{*} \mathrm{C} \#_{\varphi}\right)$ '

b. MAX-CSlOt: 'Don't delete C-slots.'

For an example, take the derivation of $\left[\mathrm{p}^{\mathrm{h}} \tilde{\mathrm{I}}\right]$ 'to roll out'. The word is phrase-final, and so N-CODA forces deletion of the nasal-associated C-slot. The vowel must still centralize, violating IDENT(ATR), otherwise it will incur a violation of CODA-SON, since it still has consonantal nasal features to its right. Candidates that delete the nasal feature entirely or allow it to remain delinked are ruled out by undominated MAX(NASAL) and *FLOAT, and are omitted from the tableau.

(19)

\begin{tabular}{|c|c|c|c|c|}
\hline$/ \mathrm{p}^{\mathrm{h}_{\mathrm{in}} /}$ & CODA-SON & N-CODA & IDENT(ATR) & MAX-CSLOT \\
\hline a. $\mathrm{p}^{\mathrm{h}}$ in & $* !$ & * & & \\
\hline b. $\mathrm{p}^{\mathrm{h}} \tilde{\mathrm{i}} \mathrm{C}$ & $* !$ & & & * \\
\hline c. $\mathrm{p}^{\mathrm{h}} \mathrm{In}$ & & $* !$ & * & \\
\hline $\mathrm{d} \cdot \mathrm{p}^{\mathrm{h}} \tilde{\mathrm{I}} \mathrm{C}$ & & & $*$ & $*$ \\
\hline
\end{tabular}

To sum up, words with underlying nasal codas always have the segmental behavior of a closed syllable, even if the syllable is phonetically open. Here, we represented this through projecting an additional CV-tier, which determines if a consonantal feature is realized a consonant (through association with a C-slot) or a suprasegmental gesture (through 
association with a V-slot). The requirement on coda-nucleus sonority (CODA-SoN) is enforced solely along the feature tier, and so vowel alternations will persist even when a consonant coda becomes suprasegmental. There are alternatives to this strategy such as output-output constraints or using a serial framework, but should pose no major problems to the present sonority-based analysis.

3.3. ImpliCATIONS: MinOR SYLLABLES. In many languages, sonority preferences for stressed syllables are inverted in stressless syllables (Kenstowicz 1994; Crosswhite 2000; a.o.). Burmese is no exception: toneless syllables (i.e. minor syllables) have inverted sonority preferences from tone-bearing syllables. While tone-bearing syllables prefer a sonority plateau between nucleus and coda, minor syllables prefer a sonority plateau between nucleus and onset, reversing the standard preferences of the Sonority Sequencing Principle. In order to accomplish this, all vowels neutralize to schwa and consonants generally voice or lose their aspiration. Preliminary data showing this is in (20). ${ }^{3}$
a. $\mathrm{t} \int \partial \theta \mathrm{r} ?$
'leopard'

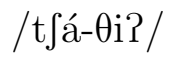
lit. tree tiger
b. bəze?
'mouth'
/pá-sa?/
lit. cheeks joining
c. $n k^{h} \tilde{a} \tilde{v}$
'nostrils'
/ nà-khón/
lit. nose cavity
d. dəbju
'pair'
/tiP-pjú/
lit. one pair

In the present account, this behavior is expected. Burmese is a language that prioritizes sonority well-formedness, which applies equally to tone-bearing and toneless syllables. In previous work, minor syllables have been puzzling: why are toneless syllables only ever schwa? Wouldn't this also be another instance of direct interaction between tone and segmental quality? The analysis here has an answer: minor syllables are but another instantiation of the sonority preferences in Burmese.

Parallel to how ordinary (tone-bearing) syllables require a moderate sonority difference between onset and nucleus, minor syllables prefer for this difference to be minimal. Instead, minor syllables prefer a sonority plateau between onset and nucleus. To accomplish this, vowels neutralize to schwa and aspirated/breathy consonants become unaspirated or voiced (21). We therefore predict that minor syllables should never have breathy or aspirated consonants, which has yet to be experimentally tested in Burmese.

(21) Sonority hierarchy - tone-bearing and toneless syllables

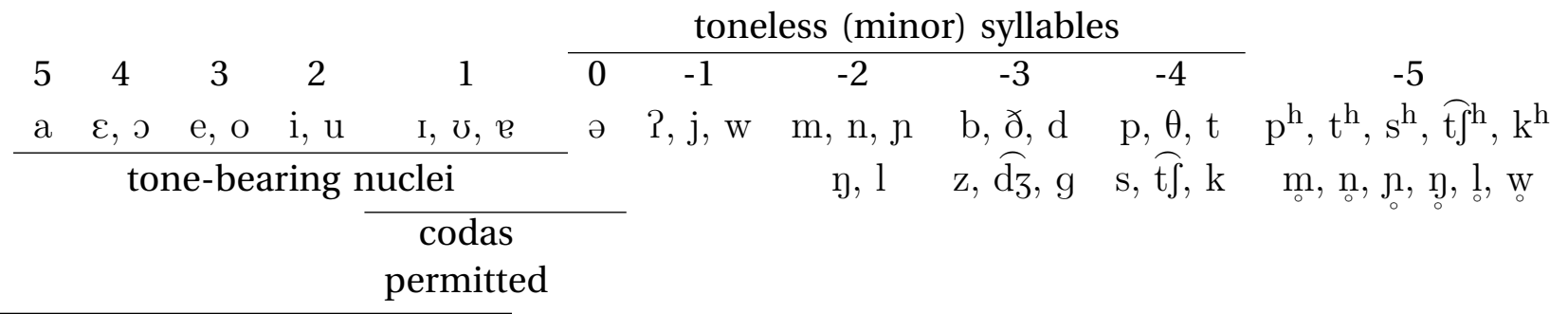

\footnotetext{
${ }^{3}$ There is some variability in the voicing of minor syllable onsets. For instance, [bəze?] 'mouth', sometimes is also pronounced with initial [p]. Future work should confirm whether this is an effect of speech rate or a broader pattern of gradience in these minor syllable alternations.
} 
3.4. IMPLICATIONS: TONE ALTERNATIONS. In terms of F0 contour, the Burmese tonal contrasts require further attention. In Section 2.1.1 and in previous work (e.g. Watkins 2000; Gruber 2011; a.o.), creaky and killed tones were found to have similar falling contours in isolation. However, the tonal contours diverged in varying prosodic contexts, where killed tones rose and creaky tones fell (Section 2.2.1). This raises the possibility that killed and creaky tones undergo some type of neutralization in isolation, so that their different underlying tonal specifications are both realized as falls.

In this account, sonority could again be the source of these alternations. de Lacy (2002) proposes a $\mathrm{H}>\mathrm{M}>\mathrm{L}$ sonority hierarchy for tones. We propose that codas are only permitted adjacent to L tones, similar to how codas are only permitted adjacent to I, $v$, e for vowels. This proposal raises the possibility that killed tones are underlyingly $\mathrm{H}$, and neutralize to HL due to the presence of a coda. This could bear on the prosodic data from Section 2.2 - creaky tones are underlyingly HL, and so they might be expected to fall in all prosodic contexts. The neutralization of killed $\mathrm{H} \rightarrow$ HL could be interrupted in some of these contexts, and instead pattern with high tones.

There are two consequences of this idea, one empirical and one formal. Empirically, this could predict that nasalized syllables should also show tonal alternations. In the acoustic study from Section 2.1, we found some evidence of this: high tones show a sharp falling contour when nasalized. While previous work hasn't reported this contrast, this is likely due to the fact that earlier studies have largely omitted nasalized syllables, focusing only on oral alternations (e.g. Watkins 2000). However, our acoustic study did not find the same alternations in low tones - they retained their fall-to-rise contour even in nasalized contexts. Further phonetic work on Burmese nasalized syllables is needed to confirm this.

Formally, this idea poses challenges for certain theories of tonal representation. While vowels are widely assumed to be decomposable into feature bundles, the featural organization of tones is more contentious (e.g. Yip 1980, Hyman 1986, et seq.). In this approach, we may also want tones to be decomposable, since this would allow us to reuse the breaking mechanism from the diphthongization cases in Section 3.1. This is more compatible with Yip's (1980) [ \pm UPPER, \pm RAISED] feature model over Hyman's L, H, HL atomic model of tone. One typological prediction this might make is that languages with a register contrast (implying featural, rather than atomic tone representation) should allow breakingtype neutralization, but that languages with no register contrast should never be able to break. This is left for future work.

3.5. Alternatives. An alternative to the analysis offered here is a mora-based approach to sonority (Hayes 1989; Zec 1995; a.o.), in which codas bring an additional mora, forcing the nucleus to reduce. However, a mora-based account is difficult to maintain with the Burmese duration data. For one, if we assume diphthongs are bimoraic, then we would expect nasalized syllables to generally be significantly longer than open syllables. However, open syllables are actually longer than nasalized ones by around $102.3 \mathrm{~ms}$ in isolation. Alternatively, we could assume that diphthongs are monomoraic, following Green (2005). However, this forces Green (2005) to stipulate (i) all final morae are placeless, and (ii) that all tone-bearing syllables are bimoraic. The main problem with this approach is minor syllables - they are not tone-bearing and so they may be only one mora, but this account does not naturally predict the onset alternations from Section 3.3. In contrast, the 
sonority-based approach here is able to account for alternations in vowel quality, tone, and onset quality in a unified fashion.

4. Conclusion. In this paper, we presented the results of two acoustic studies on Burmese tone. We confirmed some findings from previous research and expanded on this work by examining additional vowels, onsets and sentential contexts. We also found that the killed and creaky tones have different tonal contours, but that these are often neutralized in isolation. This opened up the possibility that vowel quality (the most consistent cue for distinguishing creaky and killed tones) does not need to be part of the underlying tonal specification. We then proposed that the vowel quality alternations followed from universal preferences on sonority.

This proposal has robust implications for Burmese and the wider typology of tonesegment interactions. In closed syllables, nuclei reduce their sonority to create a sonority plateau between nucleus and coda, resulting in vowel centralization or diphthongization. In toneless minor syllables, sonority preferences are inverted, and so onsets increase in sonority and nuclei reduce, creating a sonority plateau between onset and nucleus. Each of these patterns follows from application of the Sonority Sequencing Principle (Clements 1990), and draws Burmese into the larger typology of languages with sonority-based segment alternations. We thus find that Burmese tone does not directly specify segmental quality, but instead must go through a prosodic intermediary like sonority. We also are able to eliminate the underlying two-vowel system of Burmese, and instead propose that all surface alternations can arise from a single eight-vowel system.

\section{References}

Adisasmito-Smith, Niken. 1999. Influence of Javanese vowel patterning on Indonesian: An acoustic investigation. International Congress of Phonetic Sciences (ICPhS) 14. 1109-1112.

Bates, Douglas, Martin Mächler, Ben Bolker \& Steve Walker. 2014. Fitting linear mixedeffects models using lme4. Journal of Statistical Software 67(1). 1-48.

Boersma, Paul \& David Weenink. 2018. Praat: Doing phonetics by computer [Computer program]. Version 6.0. 37. http://www. praat. org/.

Bradley, David. 1982. Register in Burmese. Papers in Southeast Asian Linguistics 8. 117-132.

Clements, George N. 1990. The role of the sonority cycle in core syllabification. In John Kingston \& Mary E. Beckman (eds.), Papers in laboratory phonology, 283-333. Cambridge: Cambridge University Press. https://doi.org/10.1017/CBO9780511627736.017.

Coupe, Alexander R. 2014. Strategies for analyzing tone languages. Language Documentation 8. 28.

Crosswhite, Katherine M. 2000. Sonority-driven reduction. Annual Meeting of the Berkeley Linguistics Society (BLS) 26(1). 77-88. https://doi.org/10.3765/bls.v26i1.1155.

de Lacy, Paul. 2002. The interaction of tone and stress in Optimality Theory. Phonology 19(1). 1-32. https://doi.org/10.1017/So952675702004220.

de Lacy, Paul. 2006. Markedness: Reduction and preservation in phonology. Cambridge: Cambridge Uversity Press.

Gordon, Matthew. 2001. A typology of contour tone restrictions. Studies in Language 25(3). 423-462. https://doi.org/10.1075/sl.25.3.03gor. 
Green, Antony D. 2005. Word, foot, and syllable structure in Burmese. Studies in Burmese Linguistics (570). 1.

Gruber, James Frederick. 2011. An articulatory, acoustic, and auditory study of Burmese tone: Georgetown University dissertation.

Hayes, Bruce. 1989. Compensatory lengthening in moraic phonology. Linguistic Inquiry 20(2). 253-306.

Hyman, Larry M. 1986. The representation of multiple tone heights. The phonological representation of suprasegmentals: Studies on African languages offered to John M. Stewart on his 60th birthday, 109-152. Berlin: De Gruyter.

Kelly, Niamh Eileen. 2012. An acoustic analysis of Burmese tone. UT Austin MA thesis.

Kenstowicz, Michael. 1994. Sonority-driven stress. Manuscript. Rutgers Optimality Archive.

McCarthy, John J. 2008. The gradual path to cluster simplification. Phonology 25(2). 271-319.

McCarthy, John J. \& Alan S. Prince. 1995. Faithfulness and reduplicative identity. Papers in Optimality Theory. 10.

Parker, Stephen. 2002. Quantifying the sonority hierarchy. UMass Amherst dissertation.

Peng, Shu-hui, Marjorie KM Chan, Chiu-yu Tseng, Tsan Huang, Ok Joo Lee \& Mary E. Beckman. 2005. Towards a Pan-Mandarin system for prosodic transcription. Prosodic typology: The phonology of intonation and phrasing, 230-270. Oxford University Press.

Prince, A. \& Paul Smolensky. 1993. Optimality Theory: Constraint interaction in generative grammar. Optimality Theory in Phonology 3.

Prince, Alan \& Paul Smolensky. 2004. Optimality Theory: Constraint interaction in generative grammar. Wiley Online Library. https://doi.org/10.1002/9780470759400.

Richter, Eberhardt. 1967. Experimentelle Untersuchungen zur Theorie der Toneme im sprachlichen System des modernen Burmesischen. Wissenschaftliche Zeitschrift der Karl-Marx-Universität: Gesellschafts-und Sprachwissenschaftliche Reihe 16-1.

RStudio. 2015. RStudio: Integrated development for R. Boston, MA: RStudio, Inc. http://www. rstudio. com.

Rubach, Jerzy. 1993. The lexical phonology of Slovak. Oxford: Clarendon Press.

Shue, Yen-Liang, Patricia Keating, Chad Vicenik \& Kristine Yu. 2009. Voicesauce: A program for voice analysis. The Journal of the Acoustical Society of America 126. 2221.

Sprigg, R. K. 1964. Burmese orthography and the tonal classification of Burmese lexical items. Journal of the Burma Research Society 47(2). 415-444.

Stewart, John Alexander. 1936. An introduction to colloquial Burmese. Printed at the British Burma Press (Rangoon Gazette).

Tun, Thein. 1982. Some acoustic properties of tones in Burmese. Papers in south-east Asian linguistics 8. 77-116.

Watkins, Justin. 2000. Notes on creaky and killed tone in Burmese. SOAS Working Papers in Linguisitics and Phonetics 10. 139-149.

Watkins, Justin W. 2001. Burmese. Journal of the International Phonetic Association 31(2). 291-295. https://doi.org/10.1017/Soo25100301002122.

Yip, Moira Jean. 1980. The tonal phonology of Chinese: Cambridge, MA: MIT dissertation.

Zec, Draga. 1995. The role of moraic structure in the distribution of segments within syllables. Frontiers of phonology: Atoms, structures, derivations, 149-179.

Zoll, Cheryl. 1994. Subsegmental Parsing: Floating Features in Chaha and Yawelmani https://doi.org/10.7282/T30Z71MW. 